Etnográfica

Revista do Centro em Rede de Investigação em

Antropologia

vol. 15 (3) | 2011

Vol. 15 (3)

\title{
José Mattoso, A Dignidade: Konis Santana e a Resistência Timorense
}

\section{Kelly Silva}

\section{OpenEdition \\ Journals}

Edição electrónica

URL: https://journals.openedition.org/etnografica/1096

DOI: 10.4000/etnografica.1096

ISSN: 2182-2891

\section{Editora}

Centro em Rede de Investigação em Antropologia

\section{Edição impressa}

Data de publição: 1 outubro 2011

Paginação: 612-614

ISSN: 0873-6561

\section{Refêrencia eletrónica}

Kelly Silva, «José Mattoso, A Dignidade: Konis Santana e a Resistência Timorense», Etnográfica [Online], vol. 15 (3) | 2011, posto online no dia 23 outubro 2011, consultado o 11 fevereiro 2022. URL: http:// journals.openedition.org/etnografica/1096 ; DOI: https://doi.org/10.4000/etnografica.1096

\section{(c) (i) (8)}

Etnográfica is licensed under a Creative Commons Attribution-NonCommercial 4.0 International License. 
José Mattoso

\section{A DIGNIDADE: KONIS SANTANA E A RESISTÊNCIA TIMORENSE}

Lisboa, Temas e Debates, 2005, 323 páginas.

Eis-nos diante de uma obra fundadora da história e da sociologia da resistência leste-timorense à ocupação indonésia, desde suas configurações no interior do país. Mediante a recomposição e análise da trajetória de Konis Santana - guerrilheiro responsável pelo comando interno da luta entre, aproximadamente, abril de 1993 e março de 1998, quando veio a falecer - $A$ Dignidade apresenta ao leitor diferentes fases, tensões, disputas, estratégias, valores, atores e grupos que estruturaram as dinâmicas da resistência em seus 24 anos de atuação. Autor consagrado na historiografia da Europa Medieval, José Mattoso elabora importantes insigths ao longo da obra, explorando, por exemplo, o fundamento simbólico da guerrilha no conjunto da resistência - apesar de sua fragilidade material e numérica - e as bases cosmológicas de suas estratégias de sobrevivência e reprodução. Escrita de maneira clara e elegante, a narrativa toca os sentimentos de quem dela se aproxima. É impossível passar ileso pela narração do "cerco das pernas" e do massacre de Lakluta, por exemplo. Ao mesmo tempo, a abordagem da perspicácia e inteligência das respostas das lideranças da luta às investidas javanesas impõe ao leitor um sentimento de respeito e admiração por sua capacidade de resiliência, tornando ainda mais inteligível o fato de o sofrimento figurar como importante mobilizador político entre as populações do país (cf. Kelly Silva, 2008, "Reciprocity, recognition and suffering: political mobilizers in independent East Timor", Vibrant, 5 (2): 156-178; Elizabeth G. Traube, 2007, "Unpaid wages: local narratives and the imagination of the nation", The Asia Pacific Journal of Anthropology, 8 (1): 9-25).

A narrativa é estruturada de modo a situar a trajetória de Konis Santana na resistência e para além dela. A biografia do guerrilheiro é então construída como representando a de todos os seus companheiros de luta entre 1975 e 1998 (p. 287) e tecida a partir de fundos documentais disponibilizados por Ramos Horta, Riak Leman, Tutola e Salabae - todos personagens importantes na resistência -, além de documentos do próprio Konis Santana, entregues ao autor por Xanana Gusmão (p. 20), e narrativas orais produzidas ao longo da pesquisa que deu origem ao livro. Trata-se de uma versão autorizada da história da resistência, construída a partir do protagonismo atribuído a Xanana Gusmão e à guerrilha por ele comandada (pp. 188-189). Nesse contexto, o autor lembra que o acesso aos documentos da resistência é reservado, sendo controlado pelo governo da República Democrática de Timor-Leste (p. 23).

O livro é composto por 12 capítulos, pelos quais o leitor acompanha a conformação da trajetória de Konis e de seus companheiros na epopeia da resistência. Ao contextualizar o percurso de Konis Santana, Mattoso apresenta ao leitor as diversas fases e estruturas hierárquicas da resistência timorense em suas várias frentes de atuação - a saber: militar, clandestina e diplomática - e as disputas que as constituíam. Dada a natureza da participação de Konis na mesma como membro das Forças Armadas de Libertação Nacional de Timor-Leste (Falintil), a dinâmica e tensões da frente armada têm precedência na análise. Entre outras coisas, expõem-se as estratégias utilizadas pelas lideranças políticas e militares da luta para manterem seu comando dentro de Timor e assegurarem sua unidade pela subordinação, construída em meio a muitas tensões, das frentes diplomática e clandestina. Acompanhamos, assim, a configuração 
das Falintil em força de guerrilha e o empoderamento da Frente Clandestina, da qual ela se tornou absolutamente dependente.

Dentre as principais contribuições da obra, destaca-se a indicação do fato de as Falintil terem atuado, durante quase toda a sua existência, de maneira mais densa na região leste do país. Pode-se atribuir tal fenômeno a pelo menos dois eventos: 1) a ocupação indonésia ter-se iniciado pela fronteira terrestre de Timor com a Indonésia, portanto a oeste da metade da ilha; 2) a presença das forças militares indonésias ter sido mais efetiva também na região oeste do então Timor Timur, tornando os terrenos a leste menos vigiados durante longos períodos e assim mais propícios para a ação da guerrilha. Embora as Falintil tenham, de modo geral, operado de forma bastante frágil ao longo de todo o seu período de existência, Mattoso indica como elas foram particularmente voláteis e débeis na região oeste do país (p. 194). Quando Xanana Gusmão foi preso, em novembro de 1992, as Falintil, na região da fronteira sul, dispunham somente de quinze guerrilheiros e seis armas, e o terreno por onde podiam se deslocar tinha-se reduzido a um terço do que era anteriormente.

Não obstante, apesar de toda fragilidade, Mattoso sugere que a manutenção da guerrilha foi fundamental, na medida em que ela objetivava a resistência que alimentava a promessa de independência para os leste-timorenses que estavam dentro e fora do território. Eis um dos mais brilhantes trechos da obra: "Em suma, se, no plano simbólico, a guerrilha representava o núcleo duro da resistência, no plano prático ela não poderia subsistir sem a luta clandestina, e dificilmente atingiria seus objetivos sem a frente diplomática; era nesta que se travava a batalha decisiva. Mas se a guerrilha acabasse, quem acreditaria na independência? A população das montanhas, verdadeira alma da Resistência, considerava os aswain como os representantes do seu combate. Por isso, a luta pela independência de Timor foi verdadeiramente uma questão de resistência. Os guerrilheiros não podiam ganhar a guerra. Mas tinham que continuar a combater até à morte, porque esse era o sinal de que, enquanto resistissem, não havia solução possível para o caso de Timor. Assim, o símbolo tornou-se fundamento da realidade, e não o contrário" (p. 194).

As bases socioculturais das estratégias de sobrevivência, organização e reprodução das Falintil são também tematizadas pelo autor. Mattoso as apresenta como condicionantes importantes para o apoio popular à guerrilha e demais frentes da resistência (p. 61). Apesar da retórica revolucionária da Fretilin, inspirada em preceitos socialistas e comunistas, o autor indica que a guerrilha respeitava as hierarquias de saber e poder locais, atuando de modo solidário a elas, na maioria dos casos. O apelo a obrigações de parentesco por parte de Konis, em momentos de grande agonia, é tematizado no texto como exemplar quanto à relação de dependência da guerrilha em relação aos preceitos locais de sociabilidade, em consonância com o argumento proposto por McWilliam em "Houses of resistance in East Timor: structuring sociality in the New Nation" (Anthropological Forum, 15 (1): 27-44, 2003) - para este antropólogo, parte do sucesso da resistência timorense à ocupação indonésia no espaço das aldeias se deve às aliança entre "casas", conectadas por relações de parentesco. Mattoso identifica também a existência de uma diarquia na dinâmica da resistência já em 1976, quando o Comitê Central da Fretilin realizou sua I Reunião Plenária em Soibada (p. 63). Para cada nível de organização da luta havia uma autoridade militar e outra política.

Mas nem todos os fenômenos culturais característicos das populações do território facilitavam a atuação da guerrilha. Ao narrar 
o deslocamento de Konis para a região Haksolok, depois chamada de "Região 4", em 1986, Mattoso relata as dificuldades na construção de relações de solidariedade e apoio junto da população em razão da diversidade linguística existente (p. 125).

$\mathrm{O}$ autor arrisca-se ainda em uma narrativa sedutora, ao sugerir que o engajamento de grande parte da população timorense no apoio ou ação direta na resistência foi produzido em razão de os ocupantes terem humilhado os leste-timorenses, indo de encontro ao seu sentido de dignidade e respeito. No entanto, não há fatos históricos sustentando tal interpretação. Por sedutora que seja a sugestão - figurando quase que como uma metanarrativa -, ela esbarra primeiramente na extensão do valor da defesa da dignidade a todos que habitam as fronteiras sociopolíticas do que hoje chamamos de Timor-Leste. Mas como explicar os esforços que foram necessários para conquistar o apoio da população por parte das frentes armada e clandestina e, apesar disso, o apoio à ocupação de muitos leste-timorenses? Talvez a questão seja justamente a validade analítica de categorias

Stefania Capone

SEARCHING FOR AFRICA IN BRAZIL: POWER AND TRADITION IN CANDOMBLÉ

Durham e Londres, Duke University Press, 2010, xiv +316 páginas, trad. Lucy Lyall Grant.

Esta convincente tradução do livro La quête de l'Afrique dans le candomblé: Pouvoir et tradition au Brésil (1999) finalmente disponibiliza a antropólogos não francófonos a como "timorenses" ou "leste-timorenses". De um ponto de vista antropológico, elas nos dizem muito pouco. Em minhas investidas de pesquisa entre a elite política moderna leste-timorense, a ideia de dignidade aparece como importante mobilizador político. Seu sentido, contudo, é inverso àquele que lhe atribuímos no senso comum ocidental. Ele é muito mais próximo daquilo que nossa episteme qualifica como honra. Em tal universo empírico, dignidade significa ser reconhecido em uma certa posição hierárquica que prescreve deferência e obediência. Àqueles que a detêm cabe um decoro particular, que proíbe a ofensa ou a desconsideração aos outros em público.

Por fim, a obra de Mattoso, edificada com a colaboração de José Sequeira (Somotxo) e Florbela Marante, é também um convite a explorar mais a fundo a história da resistência - tarefa urgente, dado o desaparecimento progressivo de seus heróis e protagonistas anônimos.

\section{Kelly Silva}

Departamento de Antropologia

da Universidade de Brasília

trabalharem na área das religiões "afro" no Brasil a obra principal de Capone, cujos valor antropológico e riqueza etnográfica são incontestáveis. Capone é veterana neste contexto etnográfico, começando o seu percurso de investigação no final dos anos 80 no Rio de Janeiro, nomeadamente a partir do seu estudo de casas de Candomblé da nação Efon. Fascinada com a continuada predominância de certos modelos de pureza religiosa, como os da chamada tradição Nagô, associados às vertentes Ioruba no Candomblé, Capone dedica-se neste 